\title{
On the beginning of changes in technological and economic structure of society and prob- lems of sustainable growth of small and me- dium-sized businesses
}

\author{
Olga Priadko-Kanybekova* \\ Immanuel Kant Baltic Federal University, European Business School, Kaliningrad Region, Sovetsky \\ Prospect, 1, 236022 Kaliningrad, Russian Federation
}

\begin{abstract}
The article's subject is the changes in the technological structure of Russian society and the trends affecting the transformation of its economic structure in the context of increasing industrial development and digitalization of the state economy. The paper considers the relationships between labor productivity, economic growth, innovation, human capital, and the advantages of developed countries and big business in the specified period. One of the most important performance indicators of small and medium-sized businesses and at the same time a potential factor of their economic growth is highlighted - a change in the pattern of doing business in $\mathrm{C} 2 \mathrm{~B}, \mathrm{C} 2 \mathrm{C}, \mathrm{C} 2 \mathrm{G}$ (C2B - consumer to business, commercial activity between clients and companies; $\mathrm{C} 2 \mathrm{C}$ - consumer to consumer, commercial activity between clients (self-employed citizens); $\mathrm{C} 2 \mathrm{G}$ - consumer to government, commercial activity between self-employed citizens and government customers). Internal and external changes in the economic structure of the society that limit the growth of small and medium-sized businesses are noted. The article provides comparative data on labor productivity in Russia and the world, trends in expected growth and facts of the negative impact of restrictive coronavirus measures on the country economy. The article will be useful for representatives of small and medium-sized businesses, students and graduate students who are interested in the possibility of increasing productivity, attracting investment and impact of scientific and technical and intellectual resources on the economic growth of enterprises.
\end{abstract}

\section{Introduction}

The study's subject: current economic life of the society, economic growth rates of the leading industries, introduction of digitalization in the Russian economy and its impact on small and medium-sized businesses. Study's object: economy of the Russian Federation.

The historical background of the assessment of labor productivity originates from such authors as V. Petty, A. Smith, K. Marx, L. and F. Gilbreths. All of them contributed to the assessment of labor productivity and its impact on the production efficiency and the economy

\footnotetext{
* Corresponding author: pkou.tutor@gmail.com
} 
welfare. The terms "labor productivity" and "essence of labor productivity" are still being discussed and are acquiring new key characteristics. It is immutable that the value of labor is measured by the time it takes to produce it, and that the value depends on the labor productivity.

L. and F. Gilbrets introduced the concept of "terblig" - an elementary particle of labor activity. All labor operations consist of these particles. The dictionary developed by researchers consists of 17 units and characterizes any process of mass production. K. Marx distinguished between "productive power of labor" and "labor intensity". All this was historically discussed and eventually transformed into the now known definition of labor productivity as an indicator reflecting the efficiency of productive forces, social production, labor force and labor resources as a whole. Moreover, today, labor productivity — a factor in the competitiveness of enterprises and the global competitiveness of countries.

The last decade has been characterized by a slight positive trend in labor productivity dynamics in developed and developing countries, which is a constraint on sustainable economic growth. In Russia, statements about the need to increase labor productivity are repeatedly made at the state level and appropriate measures are taken. In particular, in July 2017, Russia adopted the program "Digital Economy of the Russian Federation". "Allocated tentative annual budget of 1.8 billion dollars, the period of implementation until 2025" [1, p. 6].

In 2019, 50 percent of the program's planned results were not achieved, and in 2021, there was a 92.1 billion-ruble reduction in the budget allocated to the 2021-2023 program to 552 billion rubles. This poses the question: is the economy digitalization really going to be more effective for small and medium-sized businesses than the current state of our society's economic structure?

The World Bank's assessment of the Russian economy once again notes: “...Russia is transitioning to a digital economy, having created a solid platform for the digital leap, including non-digital and digital factors. Building on its historic strengths: human capital, scientific achievement, strong leadership and a high level of security, the country has invested in digital infrastructure, strategic planning and regulation, and it is already paying off' [2, pp. 13-14]. What are the barriers preventing the country from joining the group of leaders in the digital economy? The average statistical pattern in the last five years shows that for two open enterprises of small and medium-sized businesses, there are ten that have closed, and the statistics do not take into account enterprises that freeze their activities (submit zero reports) and are abandoned. During the last reporting year, the situation worsened: 1.15 million enterprises closed, which is 2.3 times more than in the previous year. Small and medium-sized businesses are not ready for remote work, economy digitalization - two years of coronavirus restrictions have clearly demonstrated this.

The thing is that at the state level "it was expected the growth of labour productivity at the medium and large businesses of the basic non-primary branches of economy (industry, agriculture, transport, trade, construction) in percentage against the previous year by $103.1 \%$ in 2021 , and by 2024 - by $105 \%$ " [3, p. 1]. The dynamic growth in labor productivity was predicted on the basis of many factors, the key of which are the technical and technological development of the material production base. However, the pandemic and the decline in economic growth could significantly reduce these figures.

In the context of small and medium-sized businesses, trends in implementation of technological changes are less noticeable, since these companies do not have labor organization departments, which mainly deal with productivity issues. Small and medium-sized businesses in developed economies account for 45 to $60 \%$ of GDP; for the past five years, the share of small and medium-sized businesses in Russia's GDP has held steady at $20 \%$. President V. V. Putin, in his address to the Federal Assembly, said that by 2025 , the share of small and medium-sized businesses in the country's GDP should approach $40 \%$. According to the forecast of the national project "Small and medium-sized businesses and support of 
individual entrepreneurial initiatives", in 2024, it will be $32.5 \%$. However, the economy digitalization may hinder the achievement of this threshold.

Ethical issues are raised, since the economy digitalization, on the one hand, leads to a reduction in the cost of working time by approximately 50 times, from 200 rubles/hour to 4 rubles/hour, which is economically feasible, but, on the other hand, frees up an army of unemployed people with free time previously spent on family income. Generally accepted recommendations of authoritative sources on the distribution of released time are: free time for personal affairs, leisure, creativity, etc. The possibilities of involving the population in small business by improving conditions for self-employed citizens are considered.

\section{Materials and methods}

For the analysis, only medium and small businesses were selected that did not implement digital technologies and/or innovations due to the obvious viability of the existing business structure.

Analysis and synthesis methods were used to reproduce the work results, which ensured that the data were processed as quickly as possible and generalized conclusions were drawn. The results, as well as the average values for the evaluation of statistical data, were analyzed and summarized.

\section{Results and discussion}

What is the sectoral and technological structure of the Russian economy today? The sectoral and structural analyses conducted show that it is far from balanced economies of developed countries, as structural disproportions have accumulated and medium- and low-tech industries predominate in the areas of civilian production. Is economy digitalization really going to be more effective for small and medium-sized businesses than the current state of our society's economic structure?

Most medium and small businesses do not adopt digital technologies and/or innovations due to the obvious viability of the existing business structure. The high-tech way of life is not yet economically feasible for them. It is also worth noting that labor productivity in such enterprises is extremely low. If authoritative sources indicate that the rate of productivity growth must constantly increase and a level of at least $4 \%$ per year is desirable, as it is capable of giving an impetus to achieve the necessary rate of economic growth, then we understand that without automation and robotization of production it is no longer possible to achieve this. For example, China, with its significant workforce resources, buys 80 to 110 thousand manufacturing robots annually, including for small businesses. Russia is significantly behind in this indicator.

Currently, we are all interested in the sustainability of social development in the context of large-scale digitalization and the use of artificial intelligence technologies. Nikolai Dmitrievich Kondratiev in his work "Big Conjunctures" (1925) described conjunctural waves, indicating that each "upward" phase is replaced by "downward" one and ends with a large-scale crisis. Moreover, each upward phase includes a certain scientific and technological revolution, and we have already experienced three of them. "The transition to a new technological paradigm requires large-scale investments in fixed capital, mastering innovative technologies and modernizing the economy on their basis. Note that investment without innovation is meaningless, and sometimes even harmful, because it means investing scarce resources in the reproduction of obsolete products and technology. In essence, Russia today needs to undertake new industrialization, transformation of the entire industry on a high-tech, knowledge-intensive basis" [4, p. 7]. 
Over the past 30 years, developed countries are chasing labor productivity, automation of production, the introduction of automated control systems in enterprises. Russia is also lagging behind in these indicators. "If to modernize any modern enterprise, Japanese or German, it will give an increase in productivity of $1-3 \%$, but in Russia it is a multiple increase" $[5, \mathrm{p}$. 1]. All this thanks to the technological revolution (digitalization and artificial intelligence) sets the stage for the economic system evolution into a self-sustaining, self-organizing, nonsocial structural organism capable of producing final products and even services without the participation of its creator, man.

When calculating labor productivity in Russia, it is also necessary to take into account the size of our country. At sunset, it gets darker in the eastern regions earlier than in the western ones. In the USA, there was a time-use productivity study, the results of which were published in 2017. The authors J. Shrader and W. College has seen that when there are places that geographically force residents (such as the east) to go to bed earlier and sleep longer (the maximum difference in sunset time within the United States is about 6 hours according to the time zone division, and the actual length is $120^{\circ} 37^{\prime}$, or about 8.04 hours), then people are simply underworked compared to western areas, which, in turn, affects estimated labor productivity. "The study shows that the sun setting an hour later within an area reduces night sleep by about 20 minutes per week, which is statistically significant at the level of a $1 \%$ increase in labor productivity calculations. It has been observed that about 5 hours of change in daily sunset time in different regions determines 1.9 hours of sleep per week. In practice, this means a significant change in the use of time - about 2.1 weekly working hours lost by the average person". [6, 46-47]

The fourth scientific and technological revolution will certainly be related to the introduction of robotization, automated control systems, artificial intelligence and digitalization. Technologies honed by innovation with artificial intelligence will usher in an era of selfsustaining and self-reproducing economies. There is every indication that the fourth technological revolution that has begun will change the economic and technological mode of our society.

Measurements of economic growth and productivity are increasingly thorough, with correlations - for example, with paid taxes, accounting items, tax credits, introduction of robots, and even the average cost of welfare benefits. It was revealed that "human labor costs are so large that their increase from 80 to $83 \%$ of the total productivity changes the growth picture significantly ... although in both graphs, the proportion of input capital to the return on robotization and the use of human labor shows that the contribution of invested capital to output is significantly less on the graph without human capital" [7, p. 522].

Human capital has long been losing ground in the modern economy. Among the numerous reasons, we will mention the main ones: a person is not productive enough, not reliable enough, and not an expensive source for the system of economic reproduction. A person as a consumer is irreplaceable, but in the production chain he can be excluded. Currently, the economic development level is such that in 5-10 years we will change the classical economic model and remove some of the professions from it.

Of course, there will be a lot of moral, ethical, legal, and other issues. If we look at the recent past, it becomes clear that 10 years ago automation reached such a level that, in particular, Coca-Cola plants, including those in Russia, cost less than 10 employees. The issues of the management system automation are constantly being addressed by representatives of large businesses. If to talk about multinational corporations, these issues are solved almost everywhere. With the introduction of artificial intelligence, a person as the key link in the production chain will remain only in small and medium-sized businesses, since it is inexpensive in comparison with automation and robotics and it is simply impossible to abandon it due to limited financial resources. 


\section{Conclusions}

In the works of N.D. Kondratiev, it is argued that technological revolutions are accompanied by wars and end with large-scale crises that can last for several years. Examples include the Great Depression of 1929 or the structural economic crisis of 1971, which was accompanied by the collapse of the Bretton Woods system and the oil crisis. With our world set to change dramatically over the next 5 to 10 years, we need to prepare for massive new changes and economic realities.

"So, the need to elucidate the nature and construction of economic dynamics as opposed to statics is undeniable and realized. Because of this, static theory, no matter how perfect, is powerless to give sufficient satisfaction to the cognitive interest in economic reality and to explain the phenomenon of this reality fully enough" [8, p. 14-15].

The economic expediency of replacing human labor with machine labor and of eliminating the risks of so-called "human factor" is so great that our civilization has had to get down to the task of achieving it. The routine streamlining of economic processes on a global scale has demonstrated the peak of its human resources capabilities even with the international division of labor, labor migration, widespread retraining of personnel, and improved quality of life. The latest trends in the control system automation in production lead us to an increase in labor productivity and a multiple reduction in the number of employees. In this regard, the problems identified in the study include the additional burden on the state - especially in matters of assistance to citizens, including benefits. It is worth reflecting on and focusing on the integration of support mechanisms for the population and/or its inclusion in the new economic system.

Since the above trends will make the globalized economy more connected and human capital as a resource will eventually no longer be part of the reproduction system in the economy, and the person himself will remain mainly a consumer, the ways to solve these problems can include the stimulation of small and medium business development. The recommendation may be a change in the current business schemes B2B, B2C, B2G, G2C (B2B - business to business, commercial activity between companies; $\mathrm{B} 2 \mathrm{C}$ - business to consumer, commercial activity between companies and private customers; $\mathrm{B} 2 \mathrm{G}$ - business to government, commercial activity between companies and public customers; G2C - government to consumer commercial activity between public service centers and private customers), which is connected with their natural changes.

The consumer always wants the most individualized product. In recent decades, the range and variety of goods has shown us a overproduction crisis: there is overstocking, and examples of the disposal of new unsold goods regularly appear in the news. The manufacturer will be protected to a greater extent in case of custom work, i.e. in case of individual production. For too long we have relied on marketing and promotion, PR, public relations and advertising, whereas the possibility of individual consumption is more interesting to the customer. Thus, small and medium-sized businesses will be insured against warehouse work, overstocking, excessive advertising and marketing expenses. For example, a toothpaste made specifically for your dental health, with individually selected ingredients, is more attractive than a mass-produced product.

This approach can be used to produce any product or service. Of course, large businesses and multinational corporations cannot offer such a product, but small and medium-sized businesses can. These dramatic operating procedure changes have the potential to warp into $\mathrm{C} 2 \mathrm{~B}$, C2C, C2G, G2C, a complete U-turn from a "supply economy" and a move toward a "demand economy". This will affect environmental issues, consumption levels, and quality of life. Small and medium-sized businesses, thanks to their flexibility, can be the first to respond to this trend and develop it into an absolute competitive position. This is a convenient niche in 
which small and medium-sized businesses can find their place and bring their share of the country's GDP closer to $40 \%$.

There is also the premise that the service sector, which is occupied by small and mediumsized businesses, will be slower to adopt robotization. People as customers, as long as there is no convenient counterpart, will long prefer the service of others.

Possible areas for further research could be to address the issues of adapting the system of secondary and higher education:

— early "cupping" of endangered professions;

— training of specialists with digital competencies for small and medium-sized businesses.

Slowdown in the number of small and medium-sized businesses and their share of the country's GDP is largely related to the development of rapid technological change - hence, to achieve the goal of increasing their share to $40 \%$ of Russia's GDP, it is necessary to stimulate the development of their digital integration in the new economic environment.

\section{Acknowledgements}

I express my appreciation to Altunina V. V., Candidate of Economic Sciences, Associate Professor, for participation in personal conversations and in scientific meetings, as well as for providing various materials. I would like to express my special gratitude to Prikhodko I.Yu., my closest employee, for her constant and extremely attentive work.

\section{References}

1. Digital economy of the Russian Federation, Program, Approved by The Government Of the Russian Federation dated July 28, 2017 No. 1632-p. (2017)

2. Competition in the Digital Age: Strategic Challenges for the Russian Federation (2018)

3. Passport of the national project "Labor Productivity and Employment Support" (approved by The President the Presidential Council for Strategic Development and National Projects, Protocol No. 16 dated December 24, 2018 (2018)

4. A. A. Akaev, A.V. Korotaev, On the beginning of ascent phase of the sixth kondratiev wave and challenges of global sustainable growth, 3 (2019)

5. D. Pishchalnikov, The national project to increase labor productivity will not give growth (2021)

6. M. Gibson, J. Shrader, Time Use and Productivity: The Wage Returns to Sleep (2017)

7. V. M. Fraumeni, Measuring Economic Growth and Produc-tivity, Foundations, Klems Production Models, And (2020)

8. N. D. Kondratiev, Big conjunctures and the theory of foresight (2002)

9. A. I. Metlyakhin, N. A. Nikitina, L.V. Yarygina, E. O. Orlova, Scientific and technical statements of SPbGPU. Economic sciences, 13, 7 (2020)

10. R. M. Nureev, O. V. Karapaev, Issues of economic regulation, 10(6) (2019)

11. E. S. Sadovaya, World Economy and Int. Relations, 62, 35 (2018)

12. L. E. Grinin, A.V. Korotaev, Cycles, crises, traps of the modern World-System. The study of Kondratiev, Zhyuglyarovski and secular cycles, global crises, Malthusian and post-Malthusian traps (2012)

13. T. A. Gasanov, G. A. Gasanov, Regional problems of economic transformation, 6, 80 (2017) 
14. A. V. Sidorov, Chronoeconomics, 4(17), 64 (2019)

15. Update Human Capital Index 2020: human capital during COVID-19, World Bank report (2020)

16. B. Banke, V. Butenko, D. Mishenina, K. Polunin, A. Stepanenko, E. Sycheva, Russia online: four priorities for a breakthrough in the digital economy (2007)

17. Methodology of economic, industrial and service development in the context of digitalization, 756 (2018) 